\title{
Enhanced Electrochemical Supercapacitance of Binder-Free Nanoporous Ternary Metal oxides/metal Electrode
}

\author{
H.-J. Qiu, ${ }^{1, *}$ J. J. Gao, ${ }^{1}$ Y. R. Wen, ${ }^{2, *}$ Y. Wang ${ }^{1, *}$ \\ ${ }^{1}$ The State Key Laboratory of Mechanical Transmissions and School of Chemistry and Chemical \\ Engineering, Chongqing University, Chongqing 400044, China \\ ${ }^{2}$ Institute of Physics, Chinese Academy of Sciences, Beijing 100190, P. R. China \\ ${ }^{3}$ National Institute of Clean-and-Low-Carbon Energy, Beijing 102209, P. R. China \\ Email: hjqiu@cqu.edu.cn (H.J.Qiu) \\ wyrcsu@163.com (Y.R.Wen) \\ wangy@cqu.edu.cn (Y. Wang).
}

Abstract

Free-standing nanoporous Ni-Cu-Mn mixed metal oxides on metal with a high surface area was fabricated by chemically dealloying a $\mathrm{Ni}_{8} \mathrm{Cu}_{12} \mathrm{Mn}_{80}$ single-phase precursor, followed by electrochemical oxidation in an alkaline solution. Electrochemical analysis shows that first $\mathrm{Cu}$ and Mn-based metal oxides formed by the electrochemical oxidation. Ni-based oxides grow later with the increase of electrochemical $\mathrm{CV}$ cycles and mix with the $\mathrm{Cu} / \mathrm{Mn}$ oxides, forming a relatively stable mixed metal oxides thin film on metal ligament network. Due to the different electrochemical properties of each metal and the synergetic effect between them, the mixed ternary metal oxides formed on metal nano-ligament can operate stably between a wide potential window (1.5 V)in 1.0 $\mathrm{M} \mathrm{KOH}$ aqueous solution when tested as a free-standing supercapacitor electrode. Due to the high volumetric surface area, wide operating potential window and excellent conductivity, the nanoporous metal oxides@metal composite exhibits a high volumetric capacitance $\left(\sim 500 \mathrm{~F} \mathrm{~cm}^{-3}\right)$, high energy density $\left(\sim 38 \mathrm{~mW} \mathrm{~h} \mathrm{~cm}^{-3}\right)$ and good cycling stability. 
Keywords: dealloying; binder free; potential window; supercapacitor; volumetric capacitance

\section{Introduction}

Developing advanced electrode materials for high performance energy storage devices has attracted worldwide research interest owing to the increasing demand for renewable energy in electronic devices [1-3]. Electrochemical supercapacitors are considered to be one of the most promising energy storage devices due to their high power/energy density and long life span [2-4]. The performance of supercapacitors is mainly determined by the properties of electrode materials. Supercapacitor's energy density $(E)$ is calculated by the equation of $E=0.5 C V^{2}$, where $C$ is the specific capacitance and $V$ is the working potential window $[5,6]$. From the equation, we can see that extending the potential window is a more efficient way to enhance the overall energy density. Carbon-based materials usually exhibit an electrochemical potential window of $1.0 \mathrm{~V}$ in aqueous solutions $[7,8]$. However, since they store charges electrostatically on their surfaces, their specific capacitances are usually low. Transition metal oxides store charges with surface redox reactions and usually exhibit a high specific capacitance. However, their working potential windows are usually very narrow. For example, the working potential windows of $\mathrm{NiO}, \mathrm{Co}_{3} \mathrm{O}_{4}, \mathrm{MnO}_{2}$, etc., their sulfides are usually less than $0.8 \mathrm{~V}[4,9-21]$. To enhance the potential window of the electrodes, many efforts have been made, eg., using nonaqueous solutions as electrolytes [22-24], assembling asymmetric supercapacitors [25-31], and synthesizing new compounds.

According to the basic electrochemical behavior of transition metal oxides in an alkaline aqueous solution, nickel oxides exhibit redox reactions at positive potential part (usually 0-0.6 V vs SCE) [32], while $\mathrm{Cu}$ oxides exhibit electrochemical redox reaction mainly at negative potential part (usually -1.2 to $0.4 \mathrm{~V}$ ) [33]. Although the potential window of $\mathrm{Cu}$ oxides is relatively wide, they are not stable during the continuous electrochemical cycling process and their theoretical capacitance is quite low $[33,34]$. This is why traditionally $\mathrm{Cu}$ oxides have not been considered as a good electrode 
material for supercapacitors. In order to stabilize the $\mathrm{Cu}$-based oxides and take advantage of its wider potential window and various redox peaks, in this contribution, we carefully design a 3DNi/Cu oxides-based free-standing electrode, which contains some $\mathrm{Mn}$ oxides by chemically dealloying a Ni-Cu-Mn ternary alloy precursor followed by electrochemical oxidation in an alkaline solution. The in situ growth of nanostructured metal oxides on the highly conductive and freestanding nanoporous metal surface can guarantee the high conductivity of the formed metal oxides and also make the auxiliary components like conductive agents and binders completely unnecessary. Moreover, the presence of $\mathrm{Ni}$ and $\mathrm{Mn}$ oxides can largely stabilize $\mathrm{Cu}$ oxides due to the strong interaction between them. When tested as a free-standing 3D supercapacitor electrode, the mixed metal oxides@metal exhibits a wide operating potential window, a high volumetric capacitance, and a good cycling stability.

\section{Experimental section}

$\mathrm{Ni}_{20} \mathrm{Mn}_{80}$ and $\mathrm{Ni}_{8} \mathrm{Cu}_{12} \mathrm{Mn}_{80}$ thin alloy films were prepared by melting pure $\mathrm{Ni}, \mathrm{Cu}$ and $\mathrm{Mn}(>99.9$ at.\%) in a quartz tube, followed by injection onto a copper rotating wheel. The thin alloy films show a thickness of less than $30 \mu \mathrm{m}$. Nanoporous Ni-Mn and Ni-Cu-Mn were prepared by chemically dealloying the alloy thin film precursors in $1.0 \mathrm{M}\left(\mathrm{NH}_{4}\right)_{2} \mathrm{SO}_{4}$ aqueous solutions. The obtained nanoporous metals were then electrochemically oxidized by CV cycling from -1.0 to 0.6 (vs SCE) to form the nanoporous metal oxides on metal in $1.0 \mathrm{M} \mathrm{KOH}$ solution.

The samples were characterized by X-ray diffraction with $\mathrm{Cu} \mathrm{Ka}$ radiation, scanning electron microscopy (SEM, JEOL JSM-6700), transmission electron microscopy (TEM, JEOL ARM-200F) equipped with a probe aberration corrector (CEOS, Heidelberg, Germany) and energy-dispersive Xray spectrometer (EDS, Oxford X-Max 100TLE) and X-ray photoelectron spectroscopy (Axis Ultra with $\mathrm{Al} \mathrm{Ka}$ ).Electrochemical tests were carried out on an electrochemical workstation (CHI 660e) 
in a three-electrode cell with a Pt foil served as counter electrode, a saturated calomel electrode (SCE) as the reference electrode and the nanoporous composite as the working electrode. The electrolyte is $1.0 \mathrm{M} \mathrm{KOH}$ aqueous solution. The nominal area of the composite immersed in the electrolyte for electrochemical tests was controlled to be $\sim 0.2 \mathrm{~mm}^{-2}$. Theareal specific capacitance (C), energy density $\left(d_{e}\right)$, and power density $\left(d_{p}\right)$ were calculated by the formula,

$$
C=I \Delta t / S \Delta V(1), d_{e}=0.5 C \Delta V^{2}(2), d_{p}=d_{e} / \Delta t(3),
$$

Where $I$ is the current, $\Delta t$ is the discharge time, $\Delta V$ is the voltage range and $S$ is the nominal area of the free-standing electrode.

\section{Results and discussion}

To fabricate $\mathrm{Ni} / \mathrm{Cu}$-based nanoporous structure with a high surface area, the designed $\mathrm{Ni}_{8} \mathrm{Cu}_{12} \mathrm{Mn}_{80}$ precursor was chemically dealloyed in $1 \mathrm{M}\left(\mathrm{NH}_{4}\right)_{2} \mathrm{SO}_{4}$ aqueous solution. The selective removal of Mn would result in a 3D nanoporous metal. The SEM image (Fig. 1a) shows that the dealloyed sample possesses uniform nanoporous structure with interconnected nanoscale pores and metal ligaments. The feature size is less than $10 \mathrm{~nm}$. The nanoporous ligament-pore structure is further confirmed by the TEM characterization which shows a clear color contrast between the nanopores and ligaments (Fig. 1b). From the TEM image, it is also observed that the nanopores are filled with some thin films, which should be caused by the oxidation of the highly active nanoscale $\mathrm{Ni}-\mathrm{Cu}-\mathrm{Mn}$-based alloy ligaments and formation of metal oxides. The continuous lattice in the high-resolution TEM (HRTEM) image (Fig. 1c) indicates the crystal nature of the alloy ligaments and formed mixed metal oxides. In the metal ligaments, most lattice space is $\sim 2.09$ $\AA$, suggesting the (111) face of the $\mathrm{Ni}-\mathrm{Cu}$ alloy. On the ligament surface, the formation of a thin metal oxide is denoted by a circle. High angle annular dark-field (HAADF) scanning TEM (STEM) 
image in Fig. 1d further shows the formation of thin metal oxides on the metal ligament surface and in the pores according to the $\mathrm{Z}$ (atomic number) contrast difference (metals have high $\mathrm{Z}$ contrast than oxides which are denoted by arrows). EDS analysis shows that the besides $\mathrm{Ni}$ and $\mathrm{Cu}$, the nanoporous structure also contains $\sim 30$ at. $\%$ residual $\mathrm{Mn}$.

Electrochemical oxidation was carried out to convert the nanoporous metals into nanoporous metal oxides@metal composite. As shown in Fig. 2a, during the first CV scan, the extremely large oxidation current indicates the fast oxidation of the fresh nanoporous $\mathrm{Ni}-\mathrm{Cu}-\mathrm{Mn}$, forming a thin metal oxides/hydroxides coating on metal nano-ligaments. After the first scan, the current became smaller. The peak at around $-0.1 \mathrm{~V}$ can be ascribed to the formation of $\mathrm{Cu}(\mathrm{II})$ (probably mixed with some Mn oxides), which decreased with the increase of the scan cycles (Fig. 2b). The reduction peaks at around $-0.5 \mathrm{~V}$ and $-0.9 \mathrm{~V}$ can be assigned to the reduction of $\mathrm{Cu}(\mathrm{II})$ into $\mathrm{Cu}(\mathrm{I})$ and $\mathrm{Cu}(0)$ [33]. With the increasing $\mathrm{CV}$ cycles, the peaks corresponding to $\mathrm{NiO} / \mathrm{Ni}(\mathrm{OH})_{2}$ formation/reduction (between 0 and $0.5 \mathrm{~V}$ ) increase, which indicates the growth of $\mathrm{Ni}$ oxides mixing with the original $\mathrm{Cu}$ oxides. After around 300 cycles, the CV curves became much stable, indicating the mixed metal oxides reached a relatively stable state (Fig. 2c). All the peaks in the stabilized CV curves shift obviously form those in Fig. 2b, suggesting the strong interaction between each element in the mixed oxides. Fig. 3 shows the STEM-EDS mapping of each element in the nanoporous metal. The nano-ligament contains $\mathrm{Cu}, \mathrm{Ni}, \mathrm{Mn}$, and $\mathrm{O}$ as the main elements. It is consistent with HRTEM observation that the ligaments are covered by a thin oxide layer. In the ligaments, the $\mathrm{Ni}, \mathrm{Mn}$ and $\mathrm{O}$ elements are more homogeneously distributed than $\mathrm{Cu}$ and $\mathrm{Cu}$ is more concentrated at the center. This suggests the formation of more Ni-based oxides with the electrochemical oxidation process, which is in good agreement with the electrochemical CV signals. It is known that the formation of more oxides (resulted from the oxidation of the ligaments) would induce more Ni from under surface layer to the surface since $\mathrm{Ni}$ is more active than $\mathrm{Cu}$. 
XRD analysis shows that after dealloying the face-centered cubic single phase precursor, the three diffraction peaks (i.e., (111), (200), and (220)) shift to higher degree due to the removal of Mn with a big atomic size (Fig. 4a). The diffraction peaks also become quite broad, indicating the formation of nanoscale crystals. The appearance of another two broad peaks (denoted by star mark) can be indexed as the (111) and (220) peaks of a rock-salt-type oxide, which is formed by the electrochemical oxidation. To analyze the chemical states of each element in the formed mixed $\mathrm{Ni}$ $\mathrm{Cu}-\mathrm{Mn}$ oxides on nanoporous metal, XPS test was carried out. As shown in Fig. 4b, the surface is mainly comprised of $\mathrm{Ni}, \mathrm{Cu}, \mathrm{Mn}$, and $\mathrm{O}$. For $\mathrm{Ni}$ (Fig. 4c), the binding energy (BE) of the Ni 2p3/2 peak is at $\sim 855.5 \mathrm{eV}$ with a satellite peak at $861.2 \mathrm{eV}$, which can be ascribed to $\mathrm{Ni}^{2+}$ in the form of $\mathrm{Ni}(\mathrm{OH})_{2}$. For the spectrum of $\mathrm{Cu} 2 \mathrm{p}$ (Fig. 4d), it was concluded that both $\mathrm{Cu}^{+}(\sim 932.2 \mathrm{eV})$ and $\mathrm{Cu}^{2+}(934.5 \mathrm{eV})$ existed in the mixed oxides. The Mn 2p3/2 (Fig. 4e) exhibits a main peak at BE of $\sim 641.5 \mathrm{eV}$, suggesting that $\mathrm{MnO}_{2}$ or $\mathrm{MnOOH}$ is likely the dominant species [35]. Other species such as $\mathrm{Mn}^{2+}$ probably also exist owing to the broad feature of the peak. From the $\mathrm{O}$ 1s spectrum (Fig. 4f), one can see that most oxygen bonding states are metal-OH $(531.1 \mathrm{eV})$ and metal-O $(529.8 \mathrm{eV})$. XPS results also show that the surface Ni:Cu:Mn atomic ratio is about 37:28:35 for the nanoporous composite. The enrichment of $\mathrm{Ni}$ compared with $\mathrm{Cu}$ on the nanoporous composite surface is due to the formation of more surface oxides by the electrochemical oxidation.

The nanoporous composite electrode (i.e., mixed metal oxides@nanoporous metal) is directly used as a binder-free electrode for electrochemical supercapacitors. For comparison, we first recorded the CVs curves of nanoporous $\mathrm{Ni}$ in Fig. 5a. It is known that pure $\mathrm{NiO}$ has negligible charge/discharge currents when the potential is lower than $-0.2 \mathrm{~V}$ (vs SCE). In the present case, due to presence of some $\mathrm{Mn}$ residue, it is found that there is some small oxidation/reduction peaks between -0.4 and $0 \mathrm{~V}$ from the Ni-Mn system. For the ternary $\mathrm{Ni}-\mathrm{Cu}-\mathrm{Mn}$ system, besides a pair of peaks from Faradaic redox reactions of $\mathrm{NiO}$ (between 0 and $0.6 \mathrm{~V}$ ), some obvious redox peaks from $\mathrm{Cu} / \mathrm{Mn}$ oxides can also be observed between -1.0 and $0 \mathrm{~V}$ (Fig. 5b). The shape of the CV curves 
reveals the pseudocapacitive characteristics with several pairs of redox peaks during the long potential range from-1.0 to $0.6 \mathrm{~V}$. With the increase of the scan rates, the current increase significantly and these redox peak potentials shifted only slightly for both of the electrodes, suggesting a good rate performance, which should be due to the highly conductive metal ligament network core. The charge/discharge curves in Fig. 5c shows that the binary system exhibits a main potential plateaus at $0.2-0.4 \mathrm{~V}$. However, the ternary system shows several potential plateaus, corresponding to different redox peaks on the CV curves. At the same testing condition (i.e., the same current density and potential window), the ternary system clearly exhibits a longer charge/discharge time, indicating a higher capacitance.

The charge/discharge curves of the ternary system at different current densities and the calculated specific areal capacitances of the two samples are plotted in Fig. 5d and 5e, respectively. It can be observed that during the wide operating potential window of $1.5 \mathrm{~V}$, the nanoporous ternary system displays an areal capacitance of $\sim 1.45 \mathrm{~F} \mathrm{~cm}^{-2}$ at the current density of $5 \mathrm{~mA} \mathrm{~cm}^{-2}$, which is obviously higher than the nanoporous binary system with a capacitance of $1.17 \mathrm{~F} \mathrm{~cm}^{-2}$.Although with such a wide operating potential window of $1.5 \mathrm{~V}$, this areal capacitance is still higher than or comparable with most previously reported values for free-standing pseudocapacitive electrodes at short potential windows (usually $0-0.5 \mathrm{~V}$ ).Moreover, the specific capacitance retains $\sim 62 \%$ when the current density increases from 5 to $25 \mathrm{~mA} \mathrm{~cm}^{-2}$, which is owing to the thin oxide film formed by the electrochemical oxidation and the highly conductive metal network. In comparison, the reported $\mathrm{NiCO}_{2} \mathrm{O}_{4}$ nanoneedle@ $\mathrm{Ni}$ foam electrode decreases quickly to less than 20\% when the current density increases from 1.11 to $22.24 \mathrm{~mA} \mathrm{~cm}^{-2}$ [36]. The cycling stability of the present nanoporous ternary system is then tested under repeated charge/discharge condition at $25 \mathrm{~mA} \mathrm{~cm}{ }^{-2}$.It is found that the capacitance increased to $\sim 104 \%$ after $\sim 400$ cycles, which should be due to the slight increase in the formed metal oxides by the electrochemical condition. After 2000 cycles, the 
electrode still retains $\sim 99 \%$ of its initial value, suggesting the nanoporous ternary composite is very stable (Fig. 5f).

Since the free-standing nanoporous composite electrode is very thin (less than $30 \mu \mathrm{m}$ in thickness), the volumetric capacitance calculated is $\sim 500 \mathrm{~F} \mathrm{~cm}^{-3}$ at the current density of $5 \mathrm{~mA} \mathrm{~cm}^{-2}$. The volumetric capacitance obtained from the ternary system is much higher than most reported values, such as carbon- $\mathrm{MnO}_{2}$ composite $\left(156 \mathrm{~F} \mathrm{~cm}^{-3}\right)$ [37], $\mathrm{Ni}-\mathrm{NiO}$ nanowire film $\left(38.4 \mathrm{~F} \mathrm{~cm}^{-3}\right)$ [38], and most nanostructured carbon materials [39-41]. At $5 \mathrm{~mA} \mathrm{~cm}$, the calculated energy and power densities of the ternary composite are $\sim 38 \mathrm{mWh} \mathrm{cm}^{-3}$ and $\sim 0.32 \mathrm{Wcm}^{-3}$, respectively. The volumetric power and energy of the device are plotted in the Ragone plot in Fig. 6 along with the previously reported results. It was seen that the energy density of the present electrode is among the highest ever reported. The high volumetric energy density of the supercapacitor further indicates the efficient use of porosity within the nanoporous structure.

The enhanced electrochemical performance of the nanoporous ternary system is clearly related to the following composition and structural features. Firstly, the mixed Ni-Cu-Mn ternary oxides show different redox peaks during a wide potential window, which would greatly increase the energy density. Secondly, the small ligaments/pore size gives rise to a high effective surface area per volume, which undoubtedly contributes to the high volumetric capacitance. Thirdly, the interconnected open porosity and channels makes the electrolyte easily access to all the inner surface, which can enhance the electrochemical kinetics. Last but not least, the direct growth of the metal oxides/hydroxides film on a conductive interconnected network can ensure intimately contact, and moreover, facilitate the electron transfer from metal oxides to the metallic alloy ligaments for low internal resistance $[42,43]$.

\section{Conclusions}


A nanoporous composite (i.e., mixed $\mathrm{Ni}-\mathrm{Cu}-\mathrm{Mn}$ metal oxides on nanoscale metal) was designed and fabricated by chemical etching of a $\mathrm{Ni}_{8} \mathrm{Cu}_{12} \mathrm{Mn}_{80}$ precursor followed by an electrochemical oxidation process in an alkaline solution. Owing to the combination of $\mathrm{Cu}$ and residual $\mathrm{Mn}$, the mixed ternary oxides show obvious electrochemical redox reactions during a wide potential window of $1.5 \mathrm{~V}$. Moreover, due to the large volume specific surface area, the highly conductive alloy core network, and the uniform porous structure, the free-standing nanoporous ternary system exhibits a greatly enhanced volumetric capacitance and energy density compared with the Ni-Mn binary system and other reported values. Such nanoporous composite electrode obtained by dealloying and oxidation is scalable and may offer great promise for fabrication of high performance energy storage devices.

\section{Acknowledgements}

Financial support is from Chongqing basic and frontier research project (cstc2015jcyjA50026), Thousand Young Talents Program of the Chinese Central Government (No. 0220002102003), National Natural Science Foundation of China (NSFC, No. 21373280), Beijing National Laboratory for Molecular Sciences (BNLMS), and Hundred Talents Program at Chongqing University (No. 0903005203205). Y.R. Wen wants to thank for the National Science Foundation for Young Scientists of China (Grant No. 51501085).

\section{References}

[1] M. Winter, R.J. Brodd, What are batteries, fuel cells, and supercapacitors?, Chem. Rev., 104 (2004) 4245-4270.

[2] J.R. Miller, P. Simon, Materials science-electrochemical capacitors for energy management, science, 321 (2008) 651-652.

[3] A.S. Arico, P. Bruce, B. Scrosati, J.M. Tarascon, W. Van Schalkwijk, Nanostructured materials for advanced energy conversion and storage devices, Nat. Mater., 4 (2005) 366-377. 
[4] G. Wang, L. Zhang, J. Zhang, A review of electrode materials for electrochemical supercapacitors, Chem. Soc. Rev., 41 (2012) 797-828.

[5] Y. Wang, J. Zeng, J. Li, X. Cui, A.M. Al-Enizi, L. Zhang, G. Zheng, One-dimensional nanostructures for flexible supercapacitors, J. Mater. Chem. A, 3 (2015) 16382-16392.

[6] M. Yu, W. Qiu, F. Wang, T. Zhai, P. Fang, X. Lu, Y. Tong, Three dimensional architectures: design, assembly and application in electrochemical capacitors, J. Mater. Chem. A, 3 (2015) 1579215823 .

[7] S.W. Lee, B.M. Gallant, H.R. Byon, P.T. Hammond, Y. Shao-Horn, Nanostructured carbonbased electrodes: bridging the gap between thin-film lithium-ion batteries and electrochemical capacitors, Energ. Environ. Sci., 4 (2011) 1972-1985.

[8] A.C. Dillon, Carbon nanotubes for photoconversion and electrical energy storage, Chem. Rev., 110 (2010) 6856-6872.

[9] X.C. Dong, H. Xu, X.W. Wang, Y.X. Huang, M.B. Chan-Park, H. Zhang, L.H. Wang, W. Huang, P. Chen, 3D graphene-cobalt oxide electrode for high-performance supercapacitor and enzymeless glucose detection, ACS Nano, 6 (2012) 3206-3213.

[10] J. Kang, A. Hirata, H.J. Qiu, L. Chen, X. Ge, T. Fujita, M. Chen, Self-grown oxyhydroxide@nanoporous metal electrode for high-performance supercapacitors, Adv. Mater., 26 (2014) 269-272.

[11] H. Chen, S. Chen, M. Fan, C. Li, D. Chen, G. Tian, K. Shu, Bimetallic nickel cobalt selenides: a new kind of electroactive material for high-power energy storage, J. Mater. Chem. A, 3 (2015) 23653-23659.

[12] W. Zeng, G. Zhang, X. Wu, K. Zhang, H. Zhang, S. Hou, C. Li, T. Wang, H. Duan, Construction of hierarchical $\mathrm{CoS}$ nanowire $@ \mathrm{NiCo}_{2} \mathrm{~S}_{4}$ nanosheet arrays via one-step ion exchange for high-performance supercapacitors, J. Mater. Chem. A, 3 (2015) 24033-24040.

[13] M. Huang, F. Li, F. Dong, Y.X. Zhang, L.L. Zhang, MnO2-based nanostructures for highperformance supercapacitors, J. Mater. Chem. A, 3 (2015) 21380-21423.

[14] W. Fu, Y. Wang, W. Han, Z. Zhang, H. Zha, E. Xie, Construction of hierarchical $\mathrm{ZnCo}_{2} \mathrm{O}_{4} @ \mathrm{Ni}_{\mathrm{x}} \mathrm{Co}_{2 \mathrm{x}}(\mathrm{OH})_{6 \mathrm{x}}$ core/shell nanowire arrays for high-performance supercapacitors, J. Mater. Chem. A, (2016) DOI:10.1039/c1035ta07965a.

[15] L. Li, H. Yang, Y. Jun, L. Zhang, J. Miao, Z. Yufei, S. Chencheng, W. Huang, X.-C. Dong, B. Liu, Hierarchical carbon@ $\mathrm{Ni}_{3} \mathrm{~S}_{2} @ \mathrm{MoS}_{2}$ double core-shell nanorods for high-performance supercapacitors, J. Mater. Chem. A, (2015) DOI:10.1039/c1035ta08714g.

[16] R.P. Raj, P. Ragupathy, S. Mohan, Remarkable capacitive behavior of a $\mathrm{Co}_{3} \mathrm{O}_{4}$-polyindole composite as electrode material for supercapacitor applications, J. Mater. Chem. A, 3 (2015) 2433824348.

[17] S. Chen, M. Xue, Y. Li, Y. Pan, L. Zhu, S. Qiu, Rational design and synthesis of $\mathrm{NixCo}_{3-\mathrm{x}} \mathrm{O}_{4}$ nanoparticles derived from multivariate MOF-74 for supercapacitors, J. Mater. Chem. A, 3 (2015) 20145-20152.

[18] M. Kuang, X.Y. Liu, F. Dong, Y.X. Zhang, Tunable design of layered $\mathrm{CuCo}_{2} \mathrm{O}_{4}$ nanosheets@ $\mathrm{MnO}_{2}$ nanoflakes core-shell arrays on Ni foam for high-performance supercapacitors, J. Mater. Chem. A, 3 (2015) 21528-21536.

[19] C. Zhong, Y. Deng, W. Hu, J. Qiao, L. Zhang, J. Zhang, A review of electrolyte materials and compositions for electrochemical supercapacitors, Chem. Soc. Rev., 44 (2015) 7484-7539.

[20] Y. Zhang, L. Li, H. Su, W. Huang, X. Dong, Binary metal oxide: advanced energy storage materials in supercapacitors, J. Mater. Chem. A, 3 (2015) 43-59.

[21] Y. Zhang, C. Sun, H. Su, W. Huang, X. Dong, N-doped carbon coated hollow NixCo9-xS8 urchins for a high performance supercapacitor, Nanoscale, 7 (2015) 3155-3163.

[22] V. Aravindan, J. Gnanaraj, Y.-S. Lee, S. Madhavi, Insertion-type electrodes for nonaqueous liion capacitors, Chem. Rev., 114 (2014) 11619-11635. 
[23] S. Dong, X. Chen, L. Gu, X. Zhou, H. Xu, H. Wang, Z. Liu, P. Han, J. Yao, L. Wang, G. Cui, L. Chen, Facile preparation of mesoporous titanium nitride microspheres for electrochemical energy storage, ACS Appl. Mater. Interfaces, 3 (2011) 93-98.

[24] D.-e. Jiang, J. Wu, Microscopic insights into the electrochemical behavior of nonaqueous electrolytes in electric double-layer capacitors, J. Phys. Chem. Lett., 4 (2013) 1260-1267.

[25] H. Gao, F. Xiao, C.B. Ching, H. Duan, Flexible all-solid-state asymmetric supercapacitors based on free-standing carbon nanotube/graphene and $\mathrm{Mn}_{3} \mathrm{O}_{4}$ nanoparticle/graphene Paper electrodes, ACS Appl. Mater. Interfaces, 4 (2012) 7020-7026.

[26] X.-F. Lu, X.-Y. Chen, W. Zhou, Y.-X. Tong, G.-R. Li, $\alpha-\mathrm{Fe}_{2} \mathrm{O}_{3} @$ PANI core-shell nanowire arrays as negative electrodes for asymmetric supercapacitors, ACS Appl. Mater. Interfaces, 7 (2015) 14843-14850.

[27] X. Ren, C. Guo, L. Xu, T. Li, L. Hou, Y. Wei, Facile synthesis of hierarchical mesoporous honeycomb-like $\mathrm{NiO}$ for aqueous asymmetric supercapacitors, ACS Appl. Mater. Interfaces, 7 (2015) 19930-19940.

[28] C.-h. Tang, X. Yin, H. Gong, Superior performance asymmetric supercapacitors based on a directly grown commercial mass 3D $\mathrm{Co}_{3} \mathrm{O}_{4} @ \mathrm{Ni}(\mathrm{OH})_{2}$ core-shell electrode, ACS Appl. Mater. Interfaces, 5 (2013) 10574-10582.

[29] J. Xu, Q. Wang, X. Wang, Q. Xiang, B. Liang, D. Chen, G. Shen, Flexible asymmetric supercapacitors based upon $\mathrm{Co}_{9} \mathrm{~S}_{8}$ Nanorod $/ / \mathrm{Co}_{3} \mathrm{O}_{4} @ \mathrm{RuO}_{2}$ nanosheet arrays on carbon cloth, ACS Nano, 7 (2013) 5453-5462.

[30] V. Sahu, S. Goel, R.K. Sharma, G. Singh, Zinc oxide nanoring embedded lacey graphene nanoribbons in symmetric/asymmetric electrochemical capacitive energy storage, Nanoscale, (2015) DOI: $10.1039 / \mathrm{c} 1035 \mathrm{nr} 06083 \mathrm{~d}$.

[31] L. Zhang, H. Gong, Partial conversion of current collectors into nickel copper oxide electrode materials for high-performance energy storage devices, ACS Appl. Mater. Interfaces, 7 (2015) 15277-15284.

[32] H.J. Qiu, J.L. Kang, P. Liu, A. Hirata, T. Fujita, M.W. Chen, Fabrication of large-scale nanoporous nickel with a tunable pore size for energy storage, J. Power Sources, 247 (2014) 896905.

[33] H.J. Qiu, L. Lu, L.Y. Xue, X.R. Huang, Facile electrochemical preparation of threedimensional porous $\mathrm{Cu}$ films by potential perturbation, Electrochim. Acta, 55 (2010) 6081-6087.

[34] X. Zhang, W. Shi, J. Zhu, D.J. Kharistal, W. Zhao, B.S. Lalia, H.H. Hng, Q. Yan, High-power and high-energy-density flexible pseudocapacitor electrodes made from porous $\mathrm{CuO}$ nanobelts and single-walled carbon nanotubes, ACS Nano, 5 (2011) 2013-2019.

[35] M.C. Biesinger, B.P. Payne, A.P. Grosvenor, L.W.M. Lau, A.R. Gerson, R.S.C. Smart, Resolving surface chemical states in XPS analysis of first row transition metals, oxides and hydroxides: Cr, Mn, Fe, Co and Ni, Appl. Surf. Sci., 257 (2011) 2717-2730.

[36] G.Q. Zhang, H. Bin Wu, H.E. Hoster, M.B. Chan-Park, X.W. Lou, Single-crystalline $\mathrm{NiCo}_{2} \mathrm{O}_{4}$ nanoneedle arrays grown on conductive substrates as binder-free electrodes for high-performance supercapacitors, Energy Environ. Sci., 5 (2012) 9453-9456.

[37] A.E. Fischer, M.P. Saunders, K.A. Pettigrew, D.R. Rolison, J.W. Long, Electroless deposition of nanoscale $\mathrm{MnO}_{2}$ on ultraporous carbon nanoarchitectures: correlation of evolving pore-solid structure and electrochemical performance, J. Electrochem. Soc., 155 (2008) A246-A252.

[38] N. Liu, J. Li, W. Ma, W. Liu, Y. Shi, J. Tao, X. Zhang, J. Su, L. Li, Y. Gao, Ultrathin and lightweight 3D free-standing $\mathrm{Ni} @ \mathrm{NiO}$ nanowire membrane electrode for a supercapacitor with excellent capacitance retention at high rates, ACS Appl. Mater. Interfaces, 6 (2014) 13627-13634.

[39] J. Wang, B. Ding, Y. Xu, L. Shen, H. Dou, X. Zhang, Crumpled nitrogen-doped graphene for supercapacitors with high gravimetric and volumetric performances, ACS Appl. Mater. Interfaces, 7 (2015) 22284-22291. 
[40] H. Li, Y. Tao, X. Zheng, Z. Li, D. Liu, Z. Xu, C. Luo, J. Luo, F. Kang, Q.-H. Yang, Compressed porous graphene particles for use as supercapacitor electrodes with excellent volumetric performance, Nanoscale, 7 (2015) 18459-18463.

[41] J.-Y. Hong, J.J. Wie, Y. Xu, H.S. Park, Chemical modification of graphene aerogels for electrochemical capacitor applications, Phys Chem Chem Phys, 17 (2015) 30946-30962.

[42] X.Y. Lang, A. Hirata, T. Fujita, M.W. Chen, Nanoporous metal/oxide hybrid electrodes for electrochemical supercapacitors, Nat. Nanotechnol., 6 (2011) 232-236.

[43] T. Nguyen, S. Eugenio, M. Boudard, L. Rapenne, M.J. Carmezim, T.M. Silva, M.F. Montemor, Hybrid nickel manganese oxide nanosheet-3D metallic dendrite percolation network electrodes for high-rate electrochemical energy storage, Nanoscale, 7 (2015) 12452-12459. 


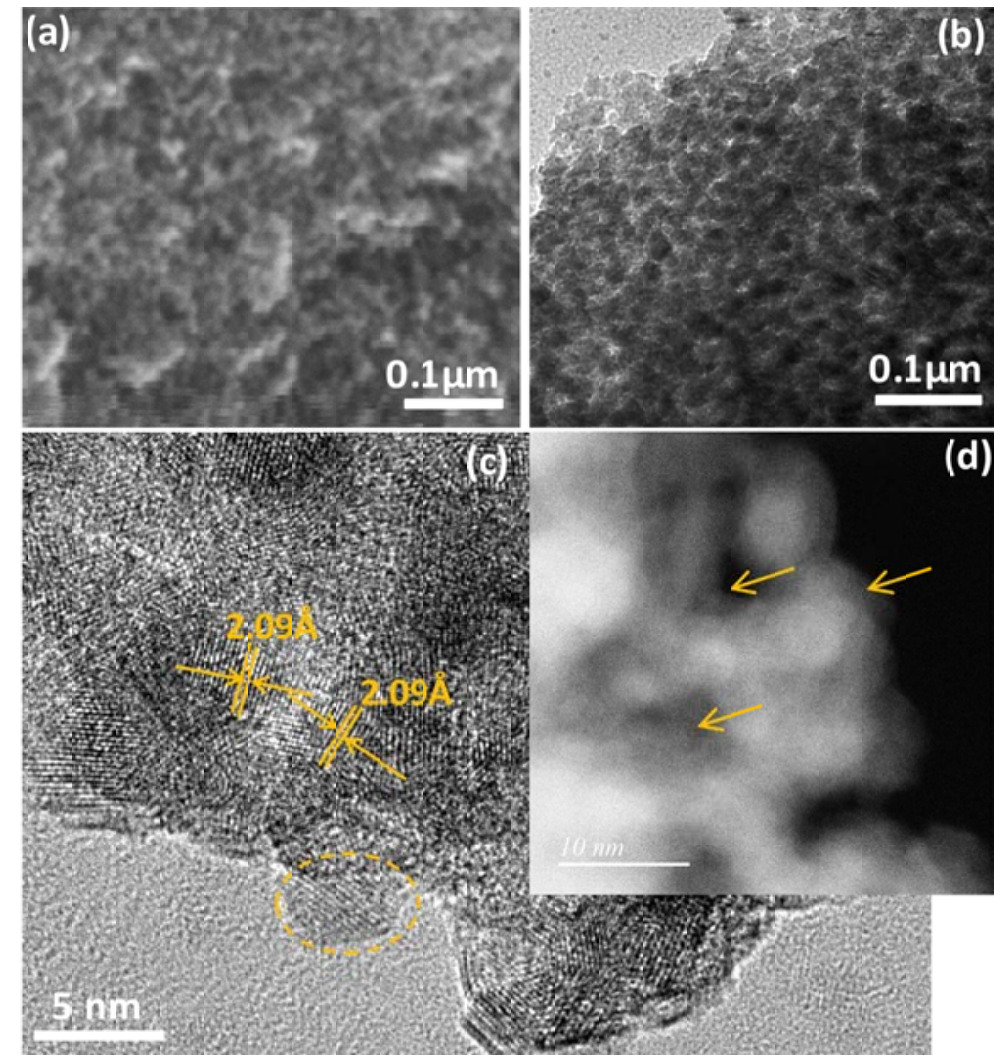

Fig. 1. SEM (a) TEM (b), HRTEM (c), and HAADF STEM (d) images of dealloyed nanoporous metals. The arrows in (d) show the formation of thin oxides films. 

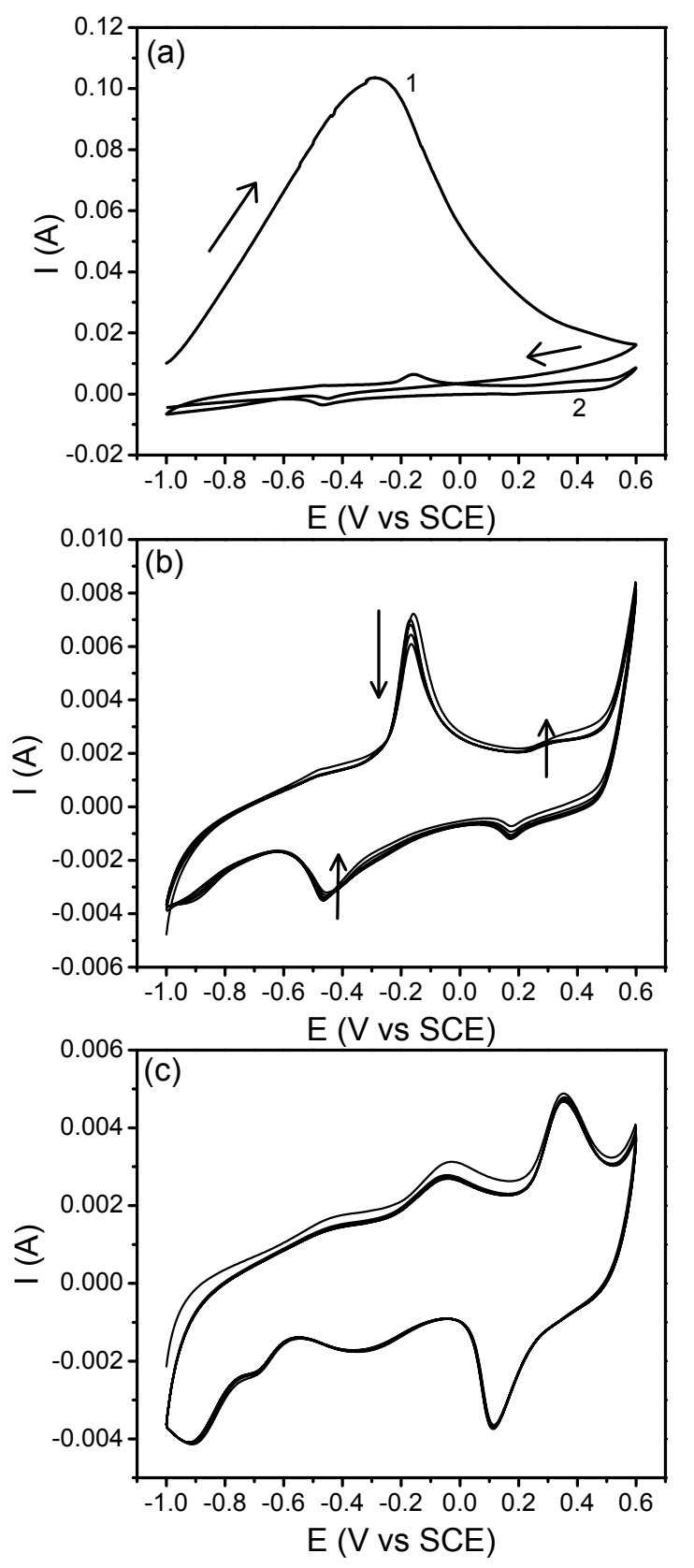

Fig. 2. CV curves of the mixed Ni-Cu-Mn oxides at different scan cycles (a: $1^{\text {st }}$ and second scan; b: third to sixth cycles; c: after 300 cycles). 

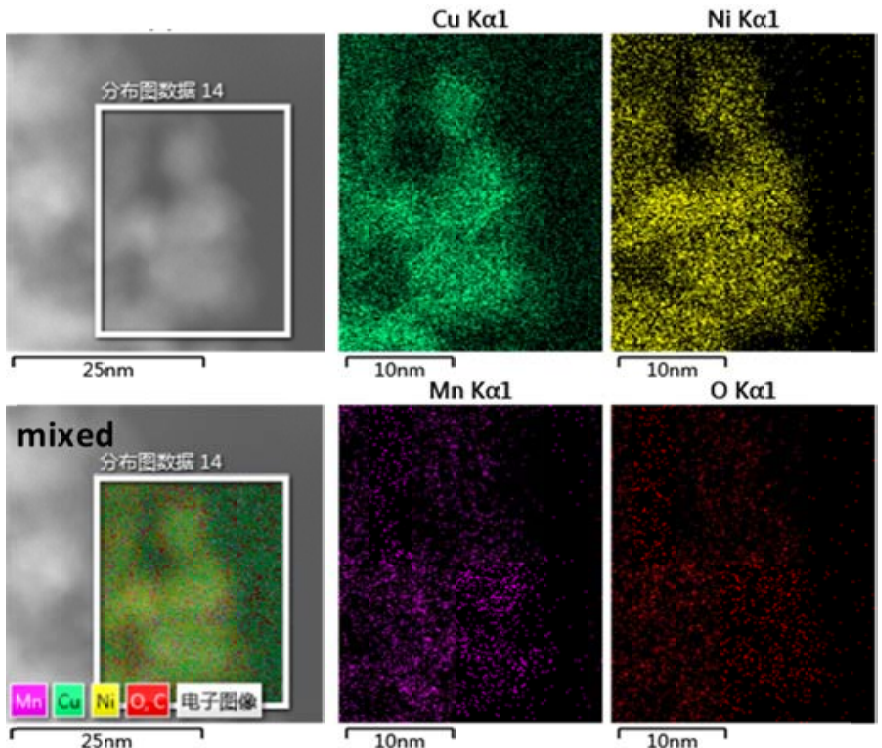

Fig. 3. STEM and EDS mapping of the nanoporous composite. 

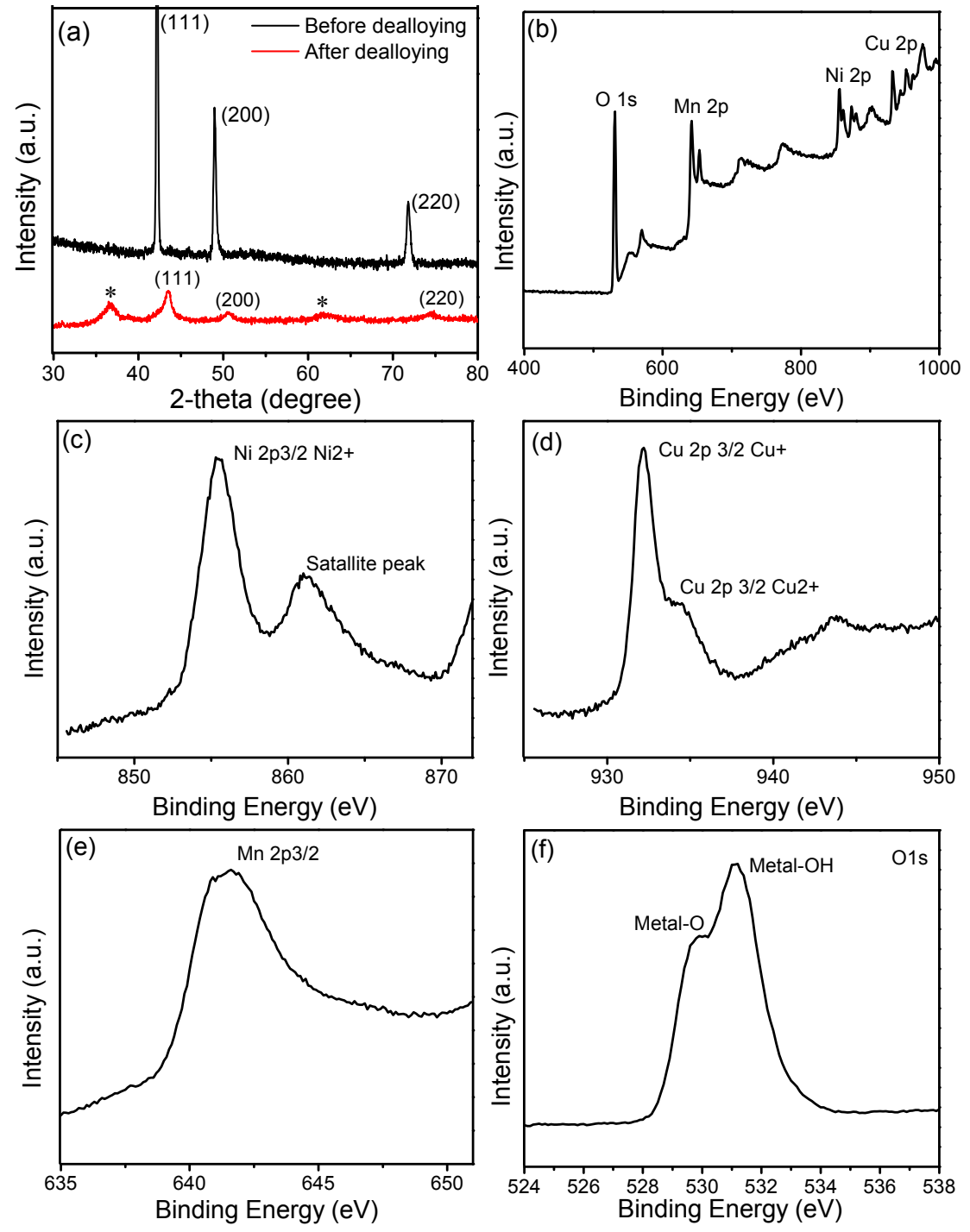

Fig. 4. XRD patterns of the ternary precursor and the metal oxides@metal composite (a). XPS survey (b) of the nanoporous composite and XPS spectra of Ni 2p (c), Cu 2p (d), Mn 2p (e) and O 1s (f). 

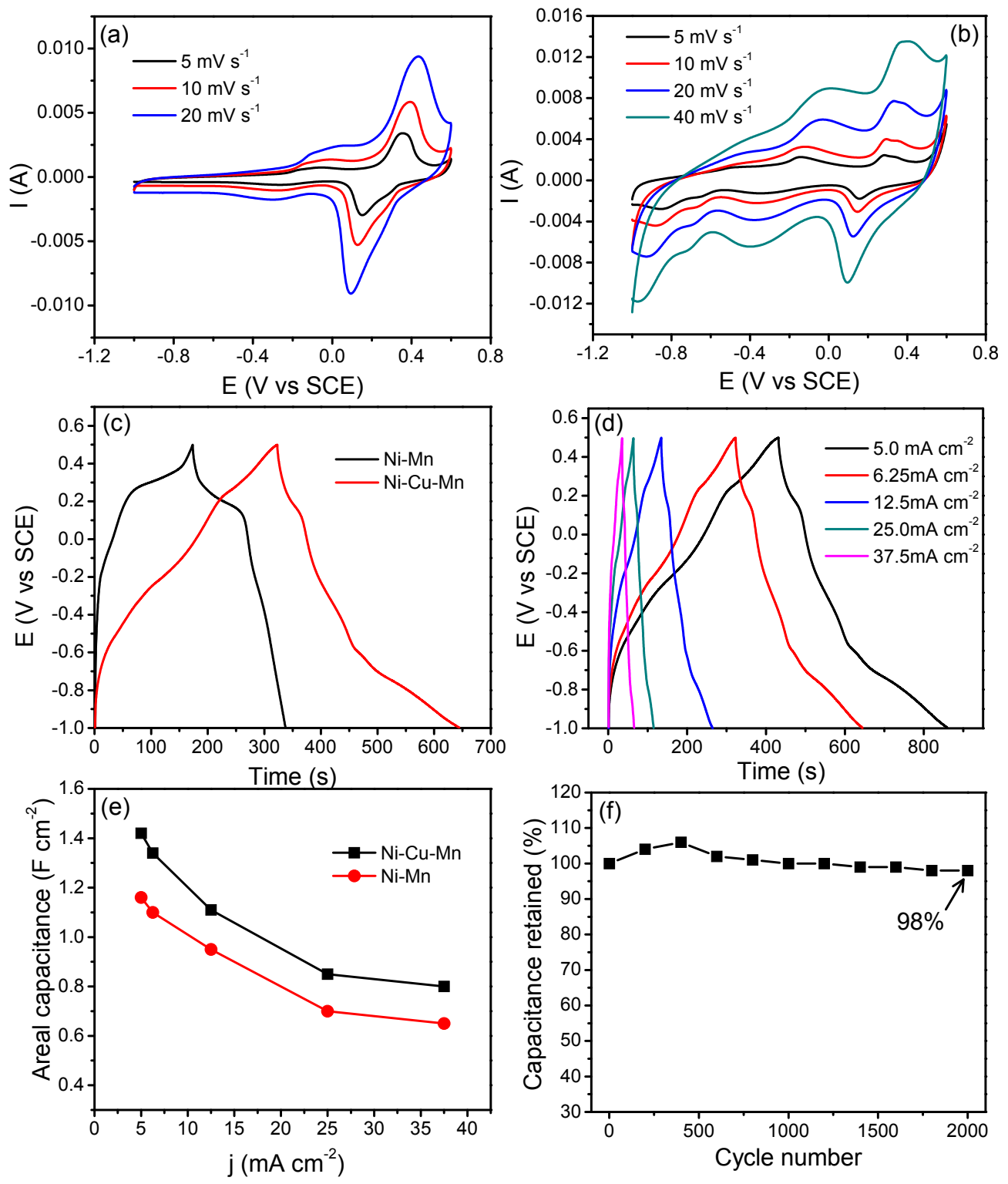

Fig. 5. CV (a: Ni-Mn oxides; b: Ni-Cu-Mn oxides) curves at different scan rates, charge-discharge (c: comparison between $\mathrm{Ni}-\mathrm{Mn}$ and $\mathrm{Ni}-\mathrm{Cu}-\mathrm{Mn}$ oxides at $6.25 \mathrm{~mA} \mathrm{~cm}{ }^{-2}$; d: Ni-Cu-Mn oxides at different scan rates) curves, areal capacitance (e) and cycling stability (f). 


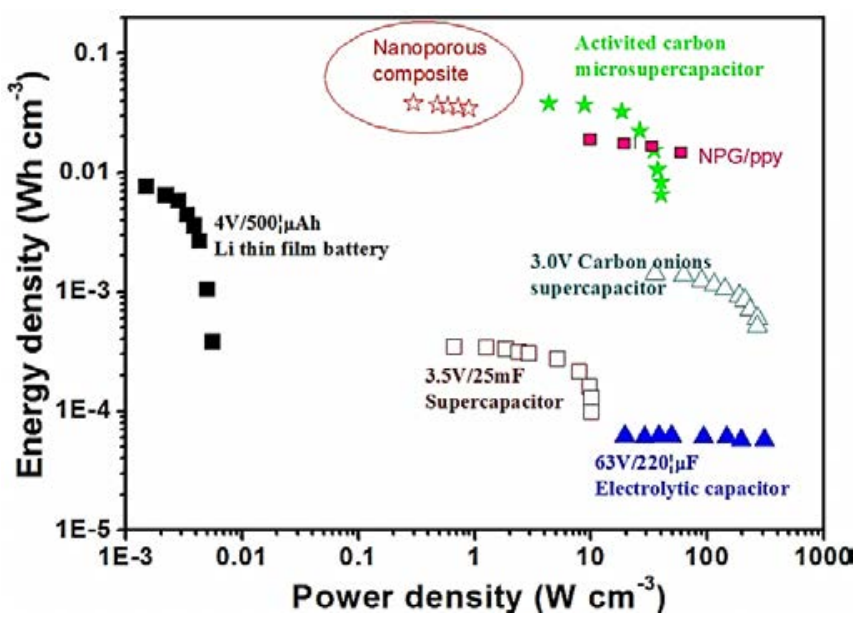

Fig. 6. Comparison of the present work (nanoporous composite) with other reported results. 